Research Article

\title{
Prevalence of Computer Vision Syndrome and Associated Factors among Instructors in Ethiopian Universities: A Web-Based Cross-Sectional Study
}

\author{
Demisu Zenbaba ${ }^{(D)},{ }^{1}$ Biniyam Sahiledengle ${ }^{D},{ }^{1}$ Mitiku Bonsa ${ }^{(D)},{ }^{1}$ Yohannes Tekalegn $\left(\mathbb{D},{ }^{1}\right.$ \\ Jember Azanaw $\mathbb{1}^{2},{ }^{2}$ and Vijay Kumar Chattu $\mathbb{C}^{3,4}$ \\ ${ }^{1}$ Madda Walabu University Goba Referral Hospital, School of Health Sciences, Department of Public Health, Bale Goba, Ethiopia \\ ${ }^{2}$ University of Gondar, College of Medicine and Health Science, \\ Department of Environmental Health and Occupational Health and Safety, Gondar, Ethiopia \\ ${ }^{3}$ Department of Medicine, Faculty of Medicine, University of Toronto, Toronto, ON M5G 2C4, Canada \\ ${ }^{4}$ Department of Public Health, Saveetha Medical College, Saveetha Institute of Medical and Technical Sciences, \\ Saveetha University, Chennai 600077, India \\ Correspondence should be addressed to Demisu Zenbaba; zdemisu@gmail.com
}

Received 19 May 2021; Accepted 21 September 2021; Published 5 October 2021

Academic Editor: Ahmad Mansour

Copyright ( $\odot 2021$ Demisu Zenbaba et al. This is an open access article distributed under the Creative Commons Attribution License, which permits unrestricted use, distribution, and reproduction in any medium, provided the original work is properly cited.

Background. In this globalized and high-tech era, the computer has become an integral part of daily life. A constant use of computer for 3 hours and more per day can cause computer vision syndrome (CVS), which is one of the leading occupational hazards of the $21^{\text {st }}$ century. The visual difficulties are the most common health problems associated with excessive computer use. Therefore, this study aimed to assess the prevalence and associated factors of CVS among instructors working in Ethiopian universities. Methods. A web-based cross-sectional study was conducted among 422 university instructors in Ethiopia from February 02 to March 24, 2021. A structured and self-administered questionnaire prepared by Google Forms was shared among instructors through their e-mail addresses, Facebook, and Telegram accounts. Data cleanup and cross-checking were done before analysis using SPSS version 23. A multivariable logistic regression was applied to identify factors associated with CVS using $p$ value $<0.05$ and $95 \%$ confidence interval. Results. Of the total 416 participants, about $293(70.4 \%)$ were reported to have CVS (95\% CI: $65.9-74.5 \%$ ), of which $54.6 \%$ were aged $24-33$ years. Blurred vision, pain in and around the eye, and eye redness were the main symptoms reported. Working in third-established universities (AOR $=8.44,95 \%$ CI: 5.47-21.45), being female $(\mathrm{AOR}=2.69,95 \%$ CI: 1.28-5.64), being 44 years old and above $(\mathrm{AOR}=2.73,95 \% \mathrm{CI}: 1.31-5.70)$, frequently working on the computer $(\mathrm{AOR}=5.51$, 95\% CI: 2.05-14.81), and sitting in bent back position (AOR $=8.10,95 \%$ CI: $2.42-23.45)$ were the factors associated with computer vision syndrome. Conclusions. In this study, nearly seven-tenths of instructors in Ethiopian universities reported having symptoms of computer vision syndrome. Working in third-generation universities, being female, age, frequently working on the computer, and sitting in bent back position were statistically significant predictors in computer vision syndrome. Therefore, optimizing exposure time, addressing ergonomic hazards associated with computer usage through on-the-job and off-the-job training, and making the safety guidelines accessible for all university instructors would be critical to address the problem.

\section{Background}

In this globalized and hi-tech era, the computer has become an integral part of daily life [1]. These devices are deliberated as the necessity of $21^{\text {st }}$ century and being used at workplaces and household level. There has been a rapid increase in computer-related health problems in the current era of prolonged and extensive computer usage [2,3]. A constant use of computer for 3 hours and more per day can cause computer vision syndrome (CVS), which is defined as a complicated eye and vision difficulty linked to the activities that stress the nearby vision during the use of a computer [4]. 
This visual difficulty may be caused by a combination of individual visual impediments, poor workstation settings, and insufficient working procedures $[5,6]$.

Computer vision syndrome is an umbrella term for many eye and environment-related disorders that arise when job-related viewing demands surpass the user's visual capabilities and is characterized by visual symptoms arising from collaboration with a computer monitor and its settings. Ninety percent of the individuals who use the computer for three to four hours daily can develop CVS, and it can be dominant with the symptoms of itching, burning, eye dryness, blurred vision, double vision, and headache that occur during or instantly after the workday [7-10].

Universally, computer vision syndrome is the leading occupational hazard of the $21^{\text {st }}$ century and one of the main public health problems. Global data show that 60 million people are suffering from CVS and one million new cases occur each year. Also, its symptoms affect almost $70 \%$ of all computer customers. It is a growing public health concern and contributes significantly to reducing the quality of life and efficiency at the workplace $[8,11,12]$. The economic effect of the visual and musculoskeletal symptoms related to computer usage is great. Underestimating the symptoms that reduce occupational productivity will result in generous financial profit. Visual difficulties are the most frequently occurring health problem related to extreme computer use [13]. Because of barrier inaccessibility and consumption of personal protective equipment, workload, and poor knowledge of ergonomics during computer use, the burden of CVS is high in developing countries such as Ethiopia [14-17].

Earlier studies conducted in different countries showed that the prevalence of CVS ranges from $64 \%$ to $90 \%$ among computer users $[16,18]$. Some of the studies conducted in Ethiopia attempted to figure out the prevalence of CVS and associated factors among computer users in different institutions; however, few individuals are aware of computer vision syndrome, its contributing factors, and simple prevention methods $[19,20]$. Factors associated with CVS were commonly categorized as (1) personal factors such as age, poor sitting position, improper viewing distances, medical diseases, taking frequent breaks, and duration of computer usage and (2) the environment which includes improper workstation, poor lighting and computer, imbalance of light between the computer screen and working room surrounding, and poor contrast [21-25].

To the best of our knowledge, the magnitude of CVS and associated factors among instructors in Ethiopia University was not well studied. Therefore, this study was designed to assess the prevalence of CVS and associated factors among instructors working in Ethiopian universities in 2021.

\section{Materials and Methods}

2.1. Study Designs, Period, and Settings. A web-based crosssectional survey was conducted among instructors working in Ethiopian universities from February 02, 2021, to March 24,2021 . Ethiopia is a large, landlocked, and diverse country with more than 90 ethnic and linguistic groups with a population of over 99 million. In Ethiopia, there are ten administrative regions and more than 80 percent of the population lives in rural areas, although there is increased urbanization as workers move from agriculture towards more productive manufacturing and services jobs. A total of 45 universities with 14 first, 23 second, and 8 third established universities are currently giving service in Ethiopia, respectively. The number of academic staff/instructors in Ethiopian universities is estimated to be 32000 [26].

2.2. Sampling and Population. The target population was all the instructors working in Ethiopian universities. The study population was all the instructors who use e-mail or social media during the data collection period. The sample size was figured out using a single population proportion formula. Considering $50 \%$ proportion, $95 \%$ level of confidence, $5 \%$ margin of error, and $10 \%$ nonresponse rate, we finally obtained 422 sample sizes.

2.3. Data Collection Tool. Data were collected through a structured, web-based, and self-administered questionnaire. First, the questionnaires were prepared in English using Google Forms by reviewing earlier studies [23, 25, 27]. The data collection tool includes sociodemographic, ergonomic practice during computer use, and computer vision syndrome items/questions.

2.4. Data Collection Methods and Procedures. The prepared Google Form link was shared with the instructors working in Ethiopian universities through their e-mail addresses, Facebook, and Telegram accounts. The Google Form was shared on official social media pages and diverse groups of Ethiopian university instructors' associations/unions to ensure equal representation of participants during the data collection process. The questionnaire became accessible after accepting the terms and conditions of the study. The link to the online Google Form is found at https://docs.google.com/forms/d/e/ 1FAIpQLSfv5rN6cUJxy6EGp0tW4yUdTuqE8amwi190i7dqC W9htmg5PA/viewform? $\mathrm{vc}=0 \& \mathrm{c}=0 \& \mathrm{w}=1 \& \mathrm{flr}=0 \& \mathrm{usp}=$ mail form_link.

2.5. Data Processing and Analysis. The responses of Google Forms were transferred to an Excel sheet and then exported to SPSS 23. Data cleanup and cross-checking were done before analysis using SPSS 23. The frequency, cross-tabulation, charts were used in descriptive analysis. All required assumptions were checked to apply multivariable logistic regression to identify factors associated with computer vision syndrome. In this regard, Hosmer and Lemeshow's model fitness test was used and multicollinearity of independent variables was checked using variance inflation factor (VIF). The variables with a $p$ value of $<0.20$ in the bivariable analysis can be a candidate for the multivariable binary logistic regression. All variables in the multivariable analysis were considered as statistically significant if $p$ value is $<0.05$ with $95 \%$ confidence level. 


\subsection{Operational Definitions}

2.6.1. Presence of Computer Vision Syndrome (CVS). In the past one year, if the respondents select at least one of the CVS symptoms such as headache, pain in and around the eye, blurred vision, dry eyes, eye redness, burning sensation, and double vision, the presence of CVS was coded as "yes $=1$ " if CVS symptoms were reported and "no $=0$ " if CVS symptoms have not been reported $[19,28]$.

2.6.2. 20-20-20 Rule for the Eye. After 20 minutes of computer usage, look at something 20 feet away for 20 seconds [29].

2.6.3. First/Second/Third Established University. The $1^{\text {st }}, 2^{\text {nd }}$, and $3^{\text {rd }}$ oldest universities established in Ethiopia were selected, respectively.

\section{Results}

3.1. Sociodemographic Characteristics. A total of 416 respondents have completed the online survey questionnaire with a participation rate of $98.6 \%$. Of these participants, about 144 (34.6\%) were from the Oromia region and 219 (52.6\%) were from second established universities. The majority $(72.4 \%)$ of respondents were males, and 227 (54.6\%) were within the age group of $24-33$ years. Concerning educational status, around $317(76.2 \%)$ of respondents attained up to the second degree or masters and 150 (36.1\%) of them were within the 1-5 service years' category (Table 1).

3.2. Ergonomic Practices during Computer Utilization. In this study, about 228 (54.8\%) respondents were reported to use laptop only. During computer utilization, around 327 (78.6\%) respondents adjust the brightness of their computer. About $43 \%$ and $83.4 \%$ of respondents work on their computer frequently and take regular breaks of 20-60 minutes per day, respectively. Concerning regular sitting position, 159 (38.2\%) respondents reported the frequent sitting position with the bent back (Table 2).

3.3. Prevalence of Computer Vision Syndrome (CVS). Among the total participants involved in the study, about 293 (70.4\%) were reported to have computer vision syndrome (95\% CI: 65.9-74.5\%). Commonly reported computer vision syndrome was blurred vision $(9.9 \%)$, pain in and around the eye (11.1\%), and eye redness (8.9\%). 134 $(32.2 \%)$ and 163 (39.2\%) respondents reported moderate and severe computer vision syndrome, respectively (Figures 1 and 2).

3.4. Factors Associated with Computer Vision Syndrome. The respondents who were working in second and third established Ethiopian universities were nearly seven and eight times more likely to develop computer vision syndrome (CVS) than those working in the first established universities $\quad(\mathrm{AOR}=7.34, \quad 95 \% \quad \mathrm{CI}: \quad 5.36-17.54$ and $\mathrm{AOR}=8.44,95 \%$ CI: 5.47-21.45), respectively. The odds of developing CVS among females were nearly three times higher than males $(\mathrm{AOR}=2.69,95 \% \mathrm{CI}: 1.28-5.64)$. The instructors within the age category of 44 years old and above were nearly 3 times more likely to develop CVS than their counterparts $(\mathrm{AOR}=2.73,95 \% \mathrm{CI}$ : 1.31-5.70). The respondents more frequently (always/often) working on their computer were 5.5 times more likely to develop CVS when compared to those working on their computer less frequently (rarely/sometimes) $\quad(\mathrm{AOR}=5.51, \quad 95 \% \quad \mathrm{CI}$ : 2.05-14.81). Regarding ergonomic practices, the instructors who more frequently sit in bent back positions were eight times more likely to report CVS than their counterparts $(\mathrm{AOR}=8.10,95 \%$ CI: 2.42-23.45). The odds of having CVS among instructors who did not use eyeglass were $68 \%$ less likely than eyeglass users $(\mathrm{AOR}=0.32,95 \% \mathrm{CI}$ : 0.15-0.67). The instructors who do not know the presence of workplace safety guidelines were nearly six times more likely to develop CVS than their counterparts $(\mathrm{AOR}=6.37,95 \% \mathrm{CI}$ : 1.68-14.34) (Table 3).

\section{Discussion}

Computer vision syndrome (CVS) is a public health problem associated with computer use. Occupational health and safety regrettably take a backseat most of the time in developing countries such as Ethiopia [29, 30]. This study was designed to assess the prevalence of CVS and associated factors among instructors in Ethiopian universities. In this study, seven out of ten respondents (70.4\%) had computer vision syndrome (CVS), with $32.2 \%$ moderate and $39.2 \%$ severe symptoms, respectively. This finding was similar to that of study conducted in Debre Tabor town, Ethiopia, $69.5 \%$ [31], and Malaysia, 68.1\% [27]. This consistency might be due to similar characteristics of respondents in computer use. These findings were less than those of a study from Chennai, India, which showed $80.3 \%$ [32]. The probable reason for the discrepancy might be either due to sociodemographic variation, study settings, and different duration of exposure to computer electromagnetic radiation. In our study, the most frequent CVS symptoms reported by instructors were redness of the eye and pain in and around the eye, followed by eye burning sensation. These study findings are found to be lower than the findings from Debre Tabor, Ethiopia [31], and India [33]. This discrepancy might be due to sampling size, study participants' age groups, and computer work duration differences.

Computer vision syndrome expressively damages workstation productivity and moderates the quality of life by assigning uncommon strain on the human physical wellbeing. Regrettably, in this study, some important variables such as duration of university establishment, sex, age, using eyeglass, frequent working, and sitting with bent back position during computer use were factors associated with computer vision syndrome. The instructors working in Ethiopian universities established at the second and third stage were more likely to develop CVS than those working in the first established universities. This observed difference 
TABLE 1: Sociodemographic characteristics of instructors in Ethiopian universities, $2021(n=416)$.

\begin{tabular}{|c|c|c|}
\hline Variables & Frequency & Percent \\
\hline \multicolumn{3}{|l|}{ Regions } \\
\hline Harari & 3 & .7 \\
\hline Sidama Zone & 4 & 1.0 \\
\hline Gambella & 9 & 2.2 \\
\hline Somali & 10 & 2.4 \\
\hline Dire Dawa & 12 & 2.9 \\
\hline Tigrai & 20 & 4.8 \\
\hline Benishangul-Gumuz & 21 & 5.0 \\
\hline SNNP & 56 & 13.5 \\
\hline Oromia & 144 & 34.6 \\
\hline \multicolumn{3}{|l|}{ Stage of university } \\
\hline First generation & 133 & 32.0 \\
\hline Second generation & 219 & 52.6 \\
\hline Third generation & 64 & 15.4 \\
\hline \multicolumn{3}{|l|}{ Sex } \\
\hline Male & 301 & 72.4 \\
\hline Female & 115 & 27.6 \\
\hline \multicolumn{3}{|l|}{ Educational status } \\
\hline First degree (BSc or BA) & 52 & 12.5 \\
\hline Second degree (Master's) & 317 & 76.2 \\
\hline Third degree $(\mathrm{PhD})$ & 47 & 11.3 \\
\hline \multicolumn{3}{|l|}{ Age } \\
\hline $24-33$ years & 227 & 54.6 \\
\hline $34-43$ years & 162 & 38.9 \\
\hline 44 years and above & 27 & 6.5 \\
\hline \multicolumn{3}{|l|}{ Service years } \\
\hline $1-5$ & 150 & 36.1 \\
\hline $6-10$ & 129 & 31.0 \\
\hline $11-15$ & 102 & 24.5 \\
\hline 16 and above & 35 & 8.4 \\
\hline
\end{tabular}

might be due to differences in the implementation of workplace safety guidelines; the most senior universities may have proper infrastructures, services, and supplies that enable instructors to minimize CVS.

The odds of having CVS among females were higher compared to males. This finding was comparable with the study finding in Malaysia, which shows that females have higher odds for CVS when compared to males [27]. This higher rate could be explained by the fact that women more frequently work on the computer and sit in inappropriate positions than males [34]. Our study has revealed that using the eyeglass was significantly associated with CVS; the odds of having CVS among instructors who did not use eyeglass were $68 \%$ less likely than eyeglass users. A potential explanation of decreased odds of CVS among those not using eyeglass might be that computer tasks are a type of near work that looks at letters on the screen without shaped tiny dots called pixels.

On the contrary, when the eyeglass is used, it is a little harder to retain the focus images while consistently working on the computer [10]. The respondents within the age category of 44 years and above were nearly 3 times more likely to develop CVS than younger participants. This might be explained by that as age increases, the probability of developing CVS also increases. This finding is inconsistent
TABLE 2: Ergonomic practices and awareness during computer use among instructors in Ethiopian universities, $2021(n=416)$.

\begin{tabular}{|c|c|c|}
\hline Items/questions & Frequency & Percent \\
\hline \multicolumn{3}{|c|}{ Types of computer used } \\
\hline Laptop only & 258 & 62.0 \\
\hline Laptop and desktop & 153 & 36.8 \\
\hline Desktop only & 5 & 1.2 \\
\hline \multicolumn{3}{|c|}{ Currently use eyeglass } \\
\hline Yes & 228 & 54.8 \\
\hline No & 188 & 45.2 \\
\hline \multicolumn{3}{|c|}{ Do you know the 20-20-20 rule for eyes? } \\
\hline Yes & 175 & 42.1 \\
\hline I do not know & 241 & 57.9 \\
\hline \multicolumn{3}{|c|}{ Is your institution having workplace safety guideline? } \\
\hline Yes & 158 & 38.0 \\
\hline No & 211 & 50.7 \\
\hline I do not know & 47 & 11.3 \\
\hline \multicolumn{3}{|c|}{ Do you always adjust the brightness of your computer? } \\
\hline Yes & 327 & 78.6 \\
\hline No & 89 & 21.4 \\
\hline \multicolumn{3}{|c|}{ How often do you work on your computer? } \\
\hline Rarely & 22 & 5.3 \\
\hline Sometimes & 57 & 13.7 \\
\hline Often & 179 & 43.0 \\
\hline Always & 158 & 38.0 \\
\hline \multicolumn{3}{|c|}{ How often is your sitting position upright with bending back? } \\
\hline Never & 21 & 5.0 \\
\hline Rarely & 61 & 14.7 \\
\hline Sometimes & 137 & 32.9 \\
\hline Often & 159 & 38.2 \\
\hline Always & 38 & 9.1 \\
\hline \multicolumn{3}{|l|}{ Health break per day } \\
\hline 20-60 minutes & 347 & 83.4 \\
\hline $61-120$ minutes & 69 & 16.6 \\
\hline
\end{tabular}

with the study finding in Malaysia, which shows that the younger age groups were at higher risk of developing CVS [27]. The respondents who were more frequently working on their computers were more likely to develop CVS when compared to those working on their computers less frequently. This might be because a computer emanates electromagnetic radiation or high-energy blue light, which stresses the ciliary muscle in the eye; eventually, a continued exposure to a computer screen causes eye stress. Thus, minimizing the duration of exposure to a computer is important to reduce CVS [10]. This study finding was comparable with that in Debre Tabor, Ethiopia [31], and elsewhere [16, 27].

Regarding ergonomic practices, the respondents who had frequent sitting positions with bending back were more likely to report CVS than their counterparts. This type of practice may reduce the distance between the eye and computer, which exposes them to more electromagnetic radiation emitting from the computer. This study finding was comparable to study findings in Gondar, Ethiopia [25]. The instructors who do not know the presence of workplace safety guidelines were more likely to develop CVS than their counterparts. This might be because they have no probability 


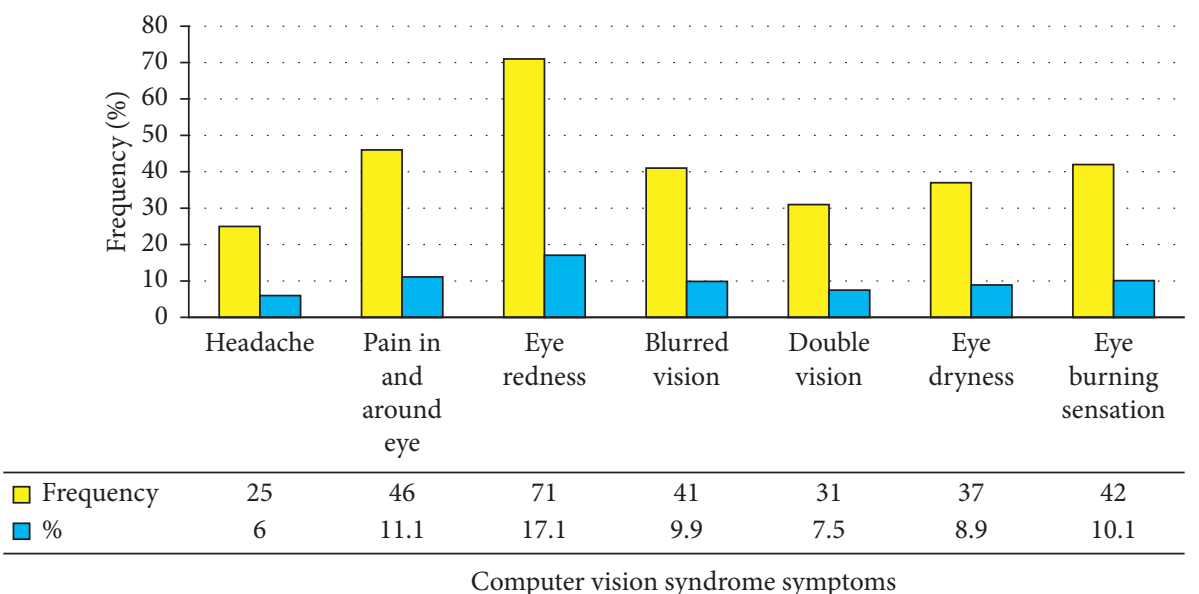

FIGURE 1: The symptoms of computer vision syndrome mentioned by university instructors in Ethiopia, 2021.

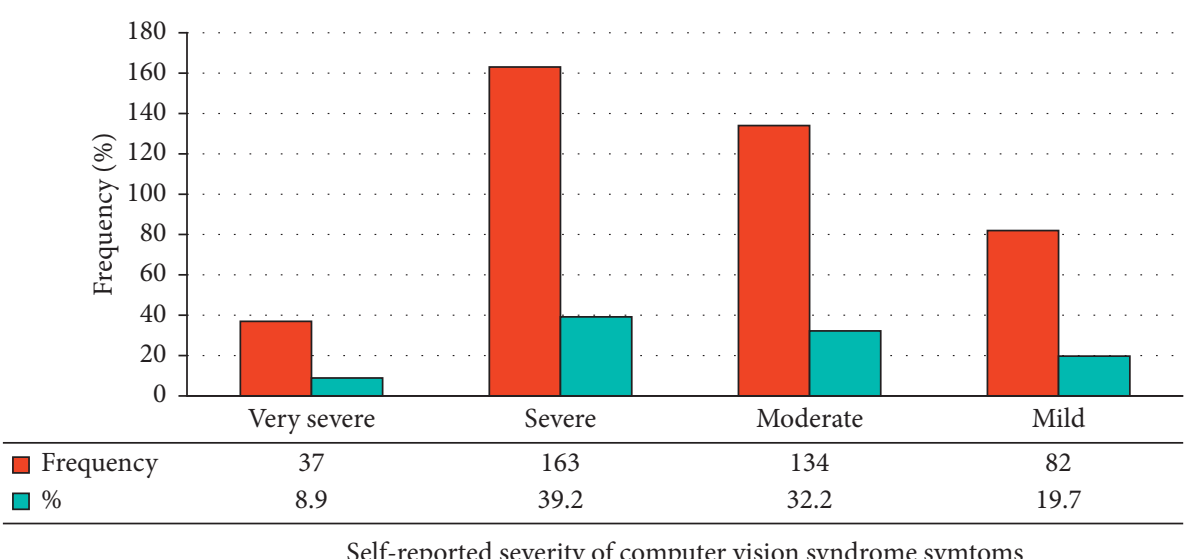

Figure 2: Self-reported severity of computer vision syndrome symptoms among instructors working in Ethiopia universities, 2021.

TABLE 3: Bivariable and multivariable logistic regression analysis for computer vision syndrome among instructors in Ethiopian universities, $2021(n=416)$.

\begin{tabular}{|c|c|c|c|c|}
\hline \multirow{2}{*}{ Variables } & \multicolumn{2}{|c|}{ Presence of CVS } & \multirow{2}{*}{ COR $(95 \% \mathrm{CI})$} & \multirow{2}{*}{$\operatorname{AOR}(95 \% \mathrm{CI})$} \\
\hline & Yes (\%) & No (\%) & & \\
\hline \multicolumn{5}{|l|}{ Sex } \\
\hline Male & $213(70.8)$ & $88(29.2)$ & 1 & 1 \\
\hline Female & $80(69.6)$ & $35(30.4)$ & $1.99(1.04-3.80)^{*}$ & $2.69(1.28-5.64)^{* *}$ \\
\hline \multicolumn{5}{|l|}{ Stage of university } \\
\hline First generation & $42(31.6)$ & $91(68.4)$ & 1 & 1 \\
\hline Second generation & $158(72.1)$ & $61(27.9)$ & $7.34(5.45-20.16)^{*}$ & $6.14(2.45-19.16)^{* *}$ \\
\hline Third generation & $44(68.8)$ & $20(31.3)$ & $6.56(4.78-18.47)^{*}$ & $5.46(3.78-16.47)^{* *}$ \\
\hline \multicolumn{5}{|l|}{ Educational status } \\
\hline First degree (BSc or BA) & $31(59.6)$ & $21(40.4)$ & 1 & \\
\hline Second degree (Master's) & $230(72.6)$ & $87(27.4)$ & $3.24(1.36-7.69)^{*}$ & \\
\hline Third degree $(\mathrm{PhD})$ & $32(68.1)$ & $15(31.9)$ & $2.71(0.86-8.58)$ & \\
\hline \multicolumn{5}{|l|}{ Age } \\
\hline $24-33$ years & $157(69.2)$ & $70(30.8)$ & 1 & 1 \\
\hline $34-43$ years & $121(74.7)$ & $41(25.3)$ & $0.36(0.11-1.16)$ & $0.62(0.16-2.41)$ \\
\hline 44 years and above & $121(74.7)$ & $41(25.3)$ & $2.35(1.25-4.38)^{*}$ & $2.73(1.31-5.70)^{* *}$ \\
\hline \multicolumn{5}{|l|}{ Currently use eyeglass } \\
\hline Yes & $162(71.1)$ & $66(28.9)$ & 1 & 1 \\
\hline No & $131(69.7)$ & $57(30.3)$ & $0.41(0.23-0.73)^{*}$ & $0.32(0.15-0.67)^{*}$ \\
\hline
\end{tabular}


TABLE 3: Continued.

\begin{tabular}{|c|c|c|c|c|}
\hline \multirow{2}{*}{ Variables } & \multicolumn{2}{|c|}{ Presence of CVS } & \multirow{2}{*}{ COR $(95 \% \mathrm{CI})$} & \multirow{2}{*}{$\operatorname{AOR}(95 \% \mathrm{CI})$} \\
\hline & Yes $(\%)$ & No $(\%)$ & & \\
\hline \multicolumn{5}{|c|}{ Types of computer used } \\
\hline Laptop only & $183(70.9)$ & $75(29.1)$ & 1 & 1 \\
\hline Laptop and desktop & $108(70.6)$ & $45(29.4)$ & $0.81(0.44-1.50)$ & $0.54(0.27-1.07)$ \\
\hline Desktop only & $2(40.0)$ & $3(60.0)$ & $0.56(0.36-0.64)^{*}$ & $0.42(0.16-0.81)^{* *}$ \\
\hline \multicolumn{5}{|l|}{ Health break per day } \\
\hline $20-60$ minutes & $242(69.7)$ & $105(30.3)$ & 1 & \\
\hline $61-120$ minutes & $51(73.9)$ & $18(26.1)$ & $1.69(0.80-3.57)$ & \\
\hline \multicolumn{5}{|c|}{ Know the 20-20-20 rule } \\
\hline Yes & $118(67.4)$ & $57(32.6)$ & 1 & \\
\hline I do not know & $118(67.4)$ & $57(32.6)$ & $1.29(0.84-1.96)$ & \\
\hline \multicolumn{5}{|c|}{ Presence of workplace safety guideline } \\
\hline Yes & $107(67.7)$ & $51(32.3)$ & 1 & $2.58(1.10-6.06)^{* *}$ \\
\hline No & $151(71.6)$ & $60(28.4)$ & $0.99(0.54-1.84)$ & $6.37(1.68-14.37)^{* *}$ \\
\hline I do not know & $12(25.5)$ & $35(74.5)$ & $2.07(0.71-6.07)$ & $2.58(1.10-6.06)^{* *}$ \\
\hline \multicolumn{5}{|c|}{ Adjust the brightness of the computer } \\
\hline Yes & $229(70.0)$ & $98(30.0)$ & 1 & \\
\hline No & $64(71.9)$ & $25(28.1)$ & $1.57(0.79-3.13)$ & 0.199 \\
\hline \multicolumn{5}{|c|}{ Duration of working on the computer } \\
\hline Rarely & $9(40.9)$ & $13(59.1)$ & 1 & 1 \\
\hline Sometimes & $33(57.9)$ & $24(42.1)$ & $0.68(0.12-1.35)$ & $1.20(0.44-3.31)$ \\
\hline Often & $132(73.7)$ & $47(26.3)$ & $2.06(1.24-6.54)^{*}$ & $3.35(1.89-8.95)^{* *}$ \\
\hline Always & $119(75.3)$ & $39(24.7)$ & $3.97(1.65-9.55)^{*}$ & $5.51(2.05-14.81)^{* *}$ \\
\hline \multicolumn{5}{|c|}{ Sitting position with bending back } \\
\hline Never & $13(61.9)$ & $8(38.1)$ & 1 & 1 \\
\hline Rarely & $39(63.9)$ & $22(36.1)$ & $0.85(0.30-2.42)$ & $0.76(0.29-1.99)$ \\
\hline Sometimes & $90(65.7)$ & $47(34.3)$ & $0.25(0.04-1.44)$ & $0.81(0.15-4.35)$ \\
\hline Often & $121(76.1)$ & $38(23.9)$ & $2.23(1.13-4.41)^{*}$ & $1.97(0.90-4.32)$ \\
\hline Always & $30(78.9)$ & $8(21.1)$ & $5.52(1.83-16.60)^{*}$ & $8.11(2.42-23.45)^{* *}$ \\
\hline
\end{tabular}

${ }^{*} p<0.05$, crude odds ratio; ${ }^{* *} p<0.05$, adjusted odds ratio.

of using/reading safety guidelines to understand ergonomic hazards and their prevention measures.

4.1. Limitation of the Study. This study has a few limitations, such as the ophthalmic checkup was not performed to measure CVS, but was based only on the self-reported symptoms. Since the study used a web-based survey, the respondents were limited to social media and Internet users. The study findings might not reveal the whole country's actual condition due to the underrepresentation of certain universities. The study might not reveal the cause-effect association between dependent and independent variables due to the study's cross-sectional nature.

\section{Conclusion}

Regardless of the above limitation, this study revealed that seven-tenth of instructors in Ethiopian universities reported symptoms of CVS. The most frequent symptoms of CVS reported by instructors were redness of eyes, pain in and around the eye, and burning sensation of the eye. The factors such as university's establishment, sex, age, eyeglass use, types of computer used, workplace safety guidelines, duration of working on the computer, and sitting in bent back position at the computer were identified as associated factors of CVS. Therefore, optimizing the exposure time and minimizing the ergonomic hazards related to computer use through proper job training by developing workplace safety guidelines and making them accessible to all instructors are essential to tackle the problem.

\section{Abbreviations}

CVS: Computer vision syndrome

AOR: Adjusted odds ratio

COR: Crude odds ratio.

\section{Data Availability}

Data will be made available from the primary author upon reasonable request.

\section{Ethical Approval}

The online survey was conducted in accordance with Helsinki Declaration after ethical clearance was obtained from the Ethical Review Board of the Madda Walabu University Goba Referral Hospital. Participants were informed to fill the online self-administered questionnaire voluntarily with a full right not to respond to all or any of the questions. The online survey has no personal identifier, so that anonymity 
was kept. The first online pages for the self-administered questionnaire could be accessed by the participants and have information to go ahead to the next page if they fully consent to take part.

\section{Conflicts of Interest}

The authors declare that they have no conflicts of interest.

\section{Authors' Contributions}

DZ participated in conception and design, acquisition of data, or analysis and interpretation of data and took part in drafting the article. BS, YT, MB, and JA participated in the sequence alignment and design of the study and performed the statistical analysis. VC conceived the study and participated in its design and coordination and helped in editing English language. All authors read and approved the final manuscript.

\section{Acknowledgments}

The authors would like to thank all study participants and Madda Walabu University for their helpful participation in this study.

\section{References}

[1] K. Mani, "Ergonomics education for office computer workers: an evidence-based strategy," in Anatomy, Posture, Prevalence, Pain, Treatment and Interventions of Musculoskeletal Disorders, O. Korhan, Ed., InTech, London, UK, First edition, 2018.

[2] H. Singh, M. J. Tigga, S. Laad, and N. Khan, "Prevention of ocular morbidity among medical students by prevalence assessment of asthenopia and its risk factors," Journal of Evidence Based Medicine and Healthcare, vol. 3, no. 15, pp. 532-536, 2016.

[3] J. Bali, N. Navin, and B. Thakur, "Computer vision syndrome: a study of the knowledge, attitudes and practices in Indian ophthalmologists," Indian Journal of Ophthalmology, vol. 55, no. 4, p. 289, 2007.

[4] A. Sen and S. Richardson, "A study of computer-related upper limb discomfort and computer vision syndrome," Journal of Human Ergology, vol. 36, no. 2, pp. 45-50, 2007.

[5] M. Millodot, Dictionary of Optometry and Visual Science E-Book, Elsevier Health Sciences, Philadelphia, PA, USA, 2014.

[6] M. Logaraj, V. Madhupriya, and S. Hegde, "Computer vision syndrome and associated factors among medical and engineering students in Chennai," Annals of Medical and Health Sciences Research, vol. 4, no. 2, pp. 179-185, 2014.

[7] M. Gangamma, M. R. Poonam, and M. Rajagopala, "A clinical study on "Computer vision syndrome" and its management with Triphala eye drops and Saptamrita Lauha," AYU (An International Quarterly Journal of Research in Ayurveda), vol. 31, no. 2, p. 236, 2010.

[8] N. A. Charpe and V. Kaushik, "Computer vision syndrome (CVS): recognition and control in software professionals," Journal of Human Ecology, vol. 28, no. 1, pp. 67-69, 2009.

[9] T. R. Akinbinu and Y. Mashalla, "Knowledge of computer vision syndrome among computer users in the workplace in Abuja, Nigeria," Journal of Physiology and Pathophysiology, vol. 4, no. 4, pp. 58-63, 2013.
[10] S. Louis, "American optometric association (AOA) the association," 2013, https://wwwaoaorg/2013 Oct 30.

[11] S. Wimalasundera, "Computer vision syndrome," Galle Medical Journal, vol. 11, no. 1, 2009.

[12] S. Tadesse, T. Kelaye, and Y. Assefa, "Utilization of personal protective equipment and associated factors among textile factory workers at Hawassa Town, Southern Ethiopia," Journal of Occupational Medicine and Toxicology, vol. 11, no. 1, pp. 1-6, 2016.

[13] J. K. Portello, M. Rosenfield, Y. Bababekova, J. M. Estrada, and A. Leon, "Computer-related visual symptoms in office workers," Ophthalmic and Physiological Optics, vol. 32, no. 5, pp. 375-382, 2012.

[14] J. R. Hayes, J. E. Sheedy, J. A. Stelmack, and C. A. Heaney, "Computer use, symptoms, and quality of life," Optometry and Vision Science, vol. 84, no. 8, pp. E738-E755, 2007.

[15] N. Shantakumari, R. Eldeeb, J. Sreedharan, and K. Gopal, "Computer use and vision-related problems among university students in Ajman, United Arab Emirate," Annals of Medical and Health Sciences Research, vol. 4, no. 2, pp. 258-263, 2014.

[16] P. Ranasinghe, W. S. Wathurapatha, Y. S. Perera et al., "Computer vision syndrome among computer office workers in a developing country: an evaluation of prevalence and risk factors," BMC Research Notes, vol. 9, no. 1, pp. 150-159, 2016.

[17] J. Anshel, Visual Ergonomics Handbook, CRC Press, Boca Raton, FL, USA, 2005.

[18] J. Bali, N. Neeraj, and R. Bali, "Computer vision syndrome: a review," Journal of clinical ophthalmology and research, vol. 2, no. 1, p. 61, 2014.

[19] M. Alemayehu, A. Nega, E. Tegegne, and Y. Mule, "Prevalence of self reported computer vision syndrome and associated factors among secretaries and data processors who are working in University of Gondar, Ethiopia," Journal of Biology, Agriculture and Healthcare, vol. 4, no. 15, 2014.

[20] M. G. Harris, J. E. Sheedy, and C. M. Gan, "Vision and task performance with monovision and diffractive bifocal contact lenses," Optometry and Vision Science: Official Publication of the American Academy of Optometry, vol. 69, no. 8, pp. 609-614, 1992.

[21] S. Agarwal, D. Goel, and A. Sharma, "Evaluation of the factors which contribute to the ocular complaints in computer users," Journal of Clinical and Diagnostic Research: Journal of Clinical and Diagnostic Research, vol. 7, no. 2, pp. 331-5, 2013.

[22] T. L. Galinsky, N. G. Swanson, S. L. Sauter, J. J. Hurrell, and L. M. Schleifer, "A field study of supplementary rest breaks for data-entry operators," Ergonomics, vol. 43, no. 5, pp. 622-638, 2000.

[23] S. C. Chiemeke, A. E. Akhahowa, and O. B. Ajayi, Eds., in Proceedings of the World Congress on Engineering, London, UK, July 2007.

[24] C. O. Ihemedu and C. O. Omolase, "The level of awareness and utilization of computer shields among computer users in a Nigerian community," Asian Journal of Medical Sciences, vol. 1, no. 2, pp. 49-52, 2010.

[25] N. L. Assefa, D. Z. Weldemichael, H. W. Alemu, and D. H. Anbesse, "Prevalence and associated factors of computer vision syndrome among bank workers in Gondar City, northwest Ethiopia, 2015," Clinical Optometry, vol. 9, p. 67, 2017.

[26] J. Salmi, A. Sursock, and A. Olefir, Improving the Performance of Ethiopian Universities in Science and Technology, World Bank, Washington, DC, USA, 2017.

[27] Z. A. Rahman and S. Sanip, "Computer user: demographic and computer related factors that predispose user to get 
computer vision syndrome," International Journal of Business, Humanities and Technology, vol. 1, no. 2, pp. 84-91, 2011.

[28] D. Bhanderi, S. Choudhary, and V. Doshi, "A communitybased study of asthenopia in computer operators," Indian Journal of Ophthalmology, vol. 56, no. 1, p. 51, 2008.

[29] R. Gyawali, M. Toomey, F. Stapleton et al., "Quality of 2019 American optometric association clinical practice guideline for diabetic eye care," Ophthalmic and Physiological Optics, vol. 41, no. 1, pp. 165-170, 2021.

[30] T. R. M. Y. Akinbinu, "Impact of computer technology on health: computer vision syndrome (CVS)," Medical Practice and Reviews, vol. 5, no. 3, pp. 20-30, 2016.

[31] A. Dessie, F. Adane, A. Nega, S. D. Wami, and D. H. Chercos, "Computer vision syndrome and associated factors among computer users in Debre Tabor town, Northwest Ethiopia," Journal of environmental and public health, vol. 2018, p. $4107590,2018$.

[32] M. Logaraj, V. M. Priya, N. Seetharaman, and S. K. Hedge, "Practice of ergonomic principles and computer vision syndrome (CVS) among under graduates students in Chennai," National Journal of Medical Research, vol. 3, no. 2, pp. 111116, 2013.

[33] R. Talwar, R. Kapoor, K. Puri, K. Bansal, and S. Singh, “A study of visual and musculoskeletal health disorders among computer professionals in NCR Delhi," Indian Journal of Community Medicine, vol. 34, no. 4, p. 326, 2009.

[34] Z. A. Rahman and A. S. Atiya, "Prevalence of work-related upper limbs symptoms (WRULS) among office workers," Asia-Pacific Journal of Public Health, vol. 21, no. 3, pp. 252258, 2009. 